\title{
Preconcentration, Separation and Multi-Elements Determination in Seawater Using a Cellulose-Zinc Hydroxide System with Inductively Coupled Plasma Atomic Emission Spectrometry
}

\author{
Ibrahim M. M. KeNAwY
}

Department of Chemistry, Faculty of Science, Mansoura University, Mansoura, Egypt

\begin{abstract}
The use of a cellulose-zinc hydroxide mixture for the micro determination of $\mathrm{Cd}(\mathrm{II}), \mathrm{Cr}(\mathrm{III}), \mathrm{Cu}(\mathrm{II}), \mathrm{Fe}$ (III), $\mathrm{Hg}(\mathrm{II})$, $\mathrm{La}(\mathrm{III}), \mathrm{Ni}(\mathrm{II}), \mathrm{Pb}(\mathrm{II}), \mathrm{Sn}(\mathrm{IV})$ and vanadate ion in a seawater sample at different $\mathrm{pH}$ was carried out employing ICP technique. The effects of concentration of $\mathrm{Zn}(\mathrm{II})$, mass of the cellulose, shaking time and the $\mathrm{pH}$ value of the sample on the preconcentration were studied. The method is simple and rapidly applicable for the microdetermination of ten heavy metals at ppb level. The effect of alkali and alkaline earth cations on the preconcentration of the tested metal ions was examined. The distribution coefficient $K_{\mathrm{d}}$ is in the range of $10^{2.86}-10^{6.31} \mathrm{~cm}^{3} \mathrm{~g}^{-1}$.
\end{abstract}

Keywords Trace metals preconcentration, seawater, cellulose-zinc hydroxide, inductively coupled atomic emission spectrometry

The excellent performance of the ICP as a multielements source allows the rapid acquisition of data on samples introduced into a plasma., ${ }^{1,2}$ Some of the attractive features of the technique are its high power of detection, large dynamic range, relative freedom from interferences and ease of operation and of multi-elements simultaneous determination. ${ }^{3-5}$ Some metals are present in environmental samples such as seawater at very low levels that are difficult to detect by inductively coupled plasma-optical emission spectrometry (ICP-OES).

The various methods of preconcentration and separation procedures, such as ion-exchange, coprecipitation and sorption, can be used prior to the ICP-OES measurements. ${ }^{6-12}$ The use of metal hydroxides such as those of iron(III), aluminum and indium as collectors for the trace elements in water samples normally produces bulky amorphous precipitates which are difficult to filter. ${ }^{13}$ Recently, cellulose-Hyphan (1-(2'-hydoxyphenylazo)-2-naphthol) was used for preconcentration of rare earth elements and noble metals from aqueous solutions. ${ }^{14,15}$

In the present work, a cellulose-zinc hydroxide system was applied for the preconcentration and microdetermination of some metals in natural water.

\section{Experimental}

\section{Reagents and solutions}

Standard solutions $\left(1000 \mu \mathrm{g} \mathrm{cm}^{-3}\right)$ of high purity (>99.99\%) metals or salts were used. Zinc reagent (10 $\mathrm{mg} \mathrm{cm}^{-3}$ ) was prepared by dissolving $\mathrm{ZnSO}_{4} \cdot 7 \mathrm{H}_{2} \mathrm{O}$ in doubly deionized distilled water. BDH cellulose and other reagents were used.

\section{Apparatus}

All the experiments were carried out ARL 3520-ICP

Table 1 Typical operation conditions for (ICP-OES) and equipment for spectral measurement

\begin{tabular}{ll} 
ICP system & ARL 3520 Switzerland \\
Power, RF generator & $27.12 \mathrm{MHz}, 2.5 \mathrm{~kW}$ \\
Argon plasma flow-rate & $121 \mathrm{~min}^{-1}$ \\
Auxiliary gas flow-rate & $0.81 \mathrm{~min}^{-1}$ \\
Nebulizer gas flow-rate & $11 \mathrm{~min}^{-1}$ \\
Sample uptake rate & $2 \mathrm{ml} \mathrm{min}^{-1}$ \\
Nebulizer & glass concentric Meinhard \\
& type \\
Monochromator & Puschen-Range mounting \\
& $(1 \mathrm{~m}$ radius) vacuum \\
& version with Ar \\
Spectral range & $170-810 \mathrm{~nm}$ \\
Grating & 1080 grooves mm-1 with \\
& reciprocal dispersion of \\
& 0.9 mm blazed at $600 \mathrm{~nm}$ \\
Speed & Displacement from one \\
& wavelength to any other \\
& wavelength is less than \\
Entrance and exit slit & $1.5 \mathrm{~s}$. \\
widths & $20 \mu \mathrm{m}$ \\
Background correction & \\
Integration time & $0.025-1 \mathrm{~nm}$ \\
\hline
\end{tabular}


equipment; the important parameters of the operating conditions are listed in Table 1. A Beckman (Fullerton, CA, USA) digital $\mathrm{pH}$ meter was used.

\section{Procedure}

Batch experiments. Transfer $5 \mathrm{~cm}^{3}$ of a mixture of the 10 heavy metals $10 \mu \mathrm{g} \mathrm{cm}^{-3}$ each, to a $50 \mathrm{~cm}^{3}$ beaker. To this solution $5 \mathrm{~cm}^{3}$ of zinc reagent was added and the $\mathrm{pH}$ was adjusted in the range 3-12 using a $5 \mathrm{~mol} \mathrm{dm}^{-3}$ $\mathrm{NaOH}$ and or $1.0 \mathrm{~mol} \mathrm{dm}^{-3}$ nitric acid. The contents were transferred to a $100 \mathrm{~cm}^{3}$ conical flask and $0.1 \mathrm{~g}$ cellulose was added to each solution. These solutions were then stirred for $20 \mathrm{~min}$ with a mechanical shaker. The precipitate was filtered through sintered glass $\left(0.45 \mu \mathrm{m}\right.$ membrane), washed with $10 \mathrm{~cm}^{3}$ of $0.2 \mathrm{~mol}$ $\mathrm{dm}^{-3} \mathrm{NaOH}$ and doubly distilled water. The formed precipitate was dissolved in $10 \mathrm{~cm}^{3}$ hot $0.5 \mathrm{~mol} \mathrm{dm}^{-3}$ nitric acid and the resulting solution was adjusted to $50 \mathrm{~cm}^{3}$ volume and directly aspirated into ICP-OES equipment. The atomic emission intensities for the elements at each $\mathrm{pH}$ value were measured. After those procedures, the effects of the masses of cellulose $(0.005-0.1 \mathrm{~g})$ and zinc sulfate $(1-200 \mathrm{mg})$ were also studied.

Determination of trace metals in seawater. One cubic decimeters of seawater, was filtered off through sintered glass $\left(0.45 \mu \mathrm{m}\right.$ membrane), then $1 \mathrm{~cm}^{3}$ of concentrated nitric acid, $5 \mathrm{~cm}^{3}$ of zinc reagent and $0.1 \mathrm{~g}$ cellulose were added. The $\mathrm{pH}$ was adjusted to a value of 9. The reaction mixture was shaken for $20 \mathrm{~min}$, the solid material was filtered off and the precipitate was then washed with $0.2 \mathrm{~mol} \mathrm{dm}^{-3} \mathrm{NaOH}$ solution. The precipitate was dissolved in hot $0.5 \mathrm{~mol} \mathrm{dm}^{-3}$ nitric acid and the concentration of each element was measured.

The calibration curves used for the determination of heavy metals by ICP-OES were done using standard solutions for the studied metal ions in the range 0.1-10 $\mu \mathrm{g} \mathrm{cm}^{-3}$, with the exception of vanadate ion: $\mathrm{Pb}^{2+}, \mathrm{Hg}^{2+}$ and $\mathrm{La}^{3+}$ which have a range of $0.2-20 \mu \mathrm{g} \mathrm{cm}^{-3}$.

\section{Results and Discussion}

\section{Analytical lines and calibration curves}

The chosen wavelengths of the analytical lines are given in Table 2. The concentrations tested in this investigation follow exactly a linear relationship between $\Delta Y_{\mathrm{x}, 0}=\log \left(I_{\mathrm{x}} / I_{0}\right)$, where $I_{\mathrm{x}}$ is the intensity of the analytical lines and $I_{0}$ is the intensity of the background ${ }^{16,17}$, and the range of concentration: in $\mu \mathrm{g} \mathrm{cm}^{-3}$, this extends from 0.1 up to at least $10 \mu \mathrm{g} \mathrm{cm}^{-3}$ of the tested multi-elements in the presence of $\mathrm{Na}^{+}+\mathrm{Mg}^{2+}$ (in the concentration level of seawater ( $c f$. Table 2)). The instrumental detection limit of the studied heavy metal ions was calculated employing this equation: ${ }^{18}$

$$
C_{\mathrm{L}}=\frac{0.01 \times K \times(\mathrm{RSD})_{\mathrm{B}} \times C_{\mathrm{o}}}{\mathrm{SBR}}
$$

Table 2 Analytical lines, analytical detection limits, $C_{\mathrm{L}} \mathrm{ng}$ $\mathrm{dm}^{-3}$, relative standard deviation in concentration, RSD and linear regression coefficient, $r$

\begin{tabular}{lcrccc}
\hline Element $^{\mathrm{a}}$ & $\begin{array}{c}\text { Wavelength/ } \\
\mathrm{nm}\end{array}$ & $\begin{array}{c}C_{\mathrm{L}} / \\
\mathrm{ng} \mathrm{dm}^{-3}\end{array}$ & $\mathrm{RSD}^{\mathrm{b}}$ & $r$ & $\eta$ \\
\hline $\mathrm{Cd}(\mathrm{I})$ & 228.80 & 2.6 & 0.02 & 0.9998 & 1.03 \\
$\mathrm{Cr}(\mathrm{II})$ & 205.55 & 14.1 & 0.08 & 0.9991 & 1.00 \\
$\mathrm{Cu}(\mathrm{I})$ & 324.75 & 5.5 & 0.10 & 0.9996 & 1.02 \\
$\mathrm{Fe}(\mathrm{II})$ & 238.20 & 4.2 & 0.18 & 0.9994 & 1.00 \\
$\mathrm{Hg}(\mathrm{II})$ & 194.23 & 3.5 & 0.02 & 0.9986 & 1.01 \\
$\mathrm{La}(\mathrm{II})$ & 379.48 & 0.80 & 0.02 & 0.9999 & 1.02 \\
$\mathrm{Ni}(\mathrm{II})$ & 231.60 & 0.60 & 0.09 & 0.9989 & 1.00 \\
$\mathrm{~Pb}(\mathrm{II})$ & 220.35 & 0.40 & 0.06 & 0.9975 & 0.67 \\
$\mathrm{Sn}(\mathrm{II})$ & 189.98 & 0.10 & 0.01 & 0.9994 & 1.08 \\
$\mathrm{~V}(\mathrm{II})$ & 309.31 & 0.90 & 0.08 & 0.9996 & 0.96 \\
\hline
\end{tabular}

$\eta$ : slope of calibration curve.

a. In the present study, a mixture of $1 \mathrm{~mol} \mathrm{dm}^{-3} \mathrm{Na}^{+}$ion +1.2 mol dm${ }^{-3} \mathrm{Mg}^{2+}$ ion was used as matrix.

b. The concentration of all the studied metal ions was $100 \mu \mathrm{g} \mathrm{dm}^{-3}$.

where $(\mathrm{RSD})_{\mathrm{B}}$ is the present relative standard deviations of the background, SBR is the signal to background ratio, $C_{O}$ is the analyte concentration at which the SBR is measured and $K$ is 2 . The detection limits are very impressive for most studied elements. The analytical detection limits were calculated by dividing instrumental detection limits by each preconcentration factor. The detection limits of these elements ranged between 0.1 and $14.1 \mathrm{ng} \mathrm{dm}^{-3}$. The analytical detection limits $\left(C_{\mathrm{L}}\right)$, $\mathrm{ng} \mathrm{dm}^{-3}$, relative standard deviation (RSD), linear regression coefficient and the slope $(\eta)$, are summarized in Table 2.

\section{Distribution coefficients $K_{d}$ for ten heavy metal ions}

The distribution coefficients are calculated by the equation

$$
K_{\mathrm{d}}=\frac{C_{\mathrm{iex}}\left(\mu \mathrm{g} \mathrm{g}^{-1}\right)}{C_{\mathrm{sol}}\left(\mu \mathrm{g} \mathrm{cm}^{-3}\right)}
$$

where $C_{\mathrm{i}, \mathrm{ex}}$ is the concentration of the metal ions in cellulose and $C_{\text {sol }}$ is that in solution. The distribution coefficients, $K_{d}$ for the studied metal ions on cellulosezinc hydroxide system as a function of $\mathrm{pH}$ are given in Table 3. In the concentration range $0.1-10 \mu \mathrm{g} \mathrm{cm}^{-3}$, the $K_{d}$ values are practically independent of the trace elements concentration. Figures $1 \mathrm{a}$ and $1 \mathrm{~b}$ summarize the relation between recovery $\%$ and $\mathrm{pH}$ values for the studied metal ions. It is clear that the $\mathrm{pH}$ has a great effect on the metal-distribution between cellulose-zinc hydroxide system and solutions. Better recoveries between $\mathrm{pH}$ range $(8-9)$ can be achieved, as is given in Table 3. The high distribution coefficients for the heavy metals on cellulose-zinc hydroxide system facilitate the separation of these metals from one sample 
Table 3 Logarithmic distribution coefficient, $K_{\mathrm{d}}$, and percent recovery, $R \%$ at different $\mathrm{pH}$ values for multi-elements ( $50 \mathrm{mg}$ of $\mathrm{Zn}^{2+}$ ion and $0.1 \mathrm{~g}$ of cellulose)

\begin{tabular}{cccc}
\hline Element & $\mathrm{pH}$ & $\log K_{\mathrm{d}}$ & $R \%$ \\
\hline $\mathrm{Cd}$ & $9^{\mathrm{a}}$ & 3.90 & $97.5^{\mathrm{a}}$ \\
& 8 & 2.86 & 78.0 \\
$\mathrm{Cr}$ & 9 & 3.64 & 95.5 \\
& 8 & 3.64 & 95.5 \\
$\mathrm{Cu}$ & 9 & 4.13 & 98.5 \\
& 8 & 4.11 & 98.4 \\
$\mathrm{Fe}$ & 9 & 3.90 & 97.5 \\
& 8 & 4.31 & 99.0 \\
$\mathrm{Hg}$ & 9 & 4.11 & 98.0 \\
& 8 & 3.44 & 93.5 \\
$\mathrm{La}$ & 9 & 4.12 & 98.3 \\
& 8 & 3.62 & 95.2 \\
$\mathrm{Ni}$ & 9 & 3.27 & 90.1 \\
& 8 & 3.03 & 84.0 \\
$\mathrm{~Pb}$ & 9 & 3.82 & 96.0 \\
& 8 & 6.29 & 99.9 \\
$\mathrm{Sn}$ & 9 & 3.90 & 97.5 \\
& 8 & 4.13 & 98.5 \\
$\mathrm{~V}$ & 9 & 3.64 & 95.5 \\
& 8 & 6.29 & 99.9 \\
\hline
\end{tabular}

a. Without cellulose as collector.

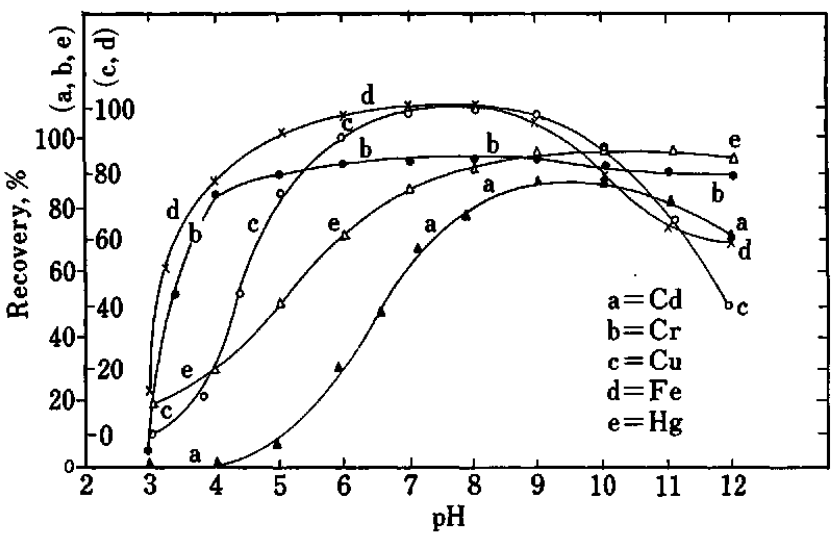

Fig. 1a Effect of change of $\mathrm{pH}$ on recoveries of $\mathrm{Cd}, \mathrm{Cr}, \mathrm{Cu}, \mathrm{Fe}$ and $\mathrm{Hg}$ (mass of cellulose $0.1 \mathrm{~g}$ and $50 \mathrm{mg}$ of $\mathrm{Zn}^{2+}$ ).

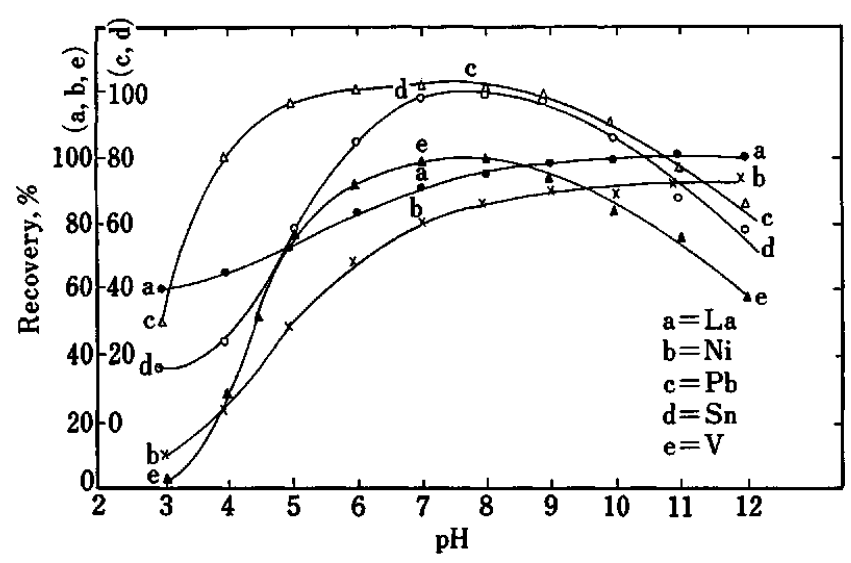

Fig. 1b Effect of change of $\mathrm{pH}$ on recoveries of $\mathrm{La}, \mathrm{Ni}, \mathrm{Pb}, \mathrm{Sn}$ and $\mathrm{V}$ (mass of cellulose $0.1 \mathrm{~g}$ and $50 \mathrm{mg}$ of $\mathrm{Zn}^{2+}$ ). solution by shaking with small amounts of the collector. The recovery of one-stage separation is given by ${ }^{14,15}$

$$
P=\frac{K_{\mathrm{d}} m_{\mathrm{czn}}}{K_{\mathrm{d}} m_{\mathrm{czn}}+V_{\mathrm{L}}}
$$

where $m_{\mathrm{czn}}$ is the mass of cellulose and zinc sulfate and $V_{\mathrm{L}}$ is the volume of solution $\left(50 \mathrm{~cm}^{3}\right)$. The recovery depends on the $\mathrm{pH}$ values of solutions. At the maximum values of $K_{\mathrm{d}}$ the following recoveries are obtained: $97.5 \% \mathrm{Cd}, 95.5 \% \mathrm{Cr}, 98.5 \% \mathrm{Cu}, 99.0 \% \mathrm{Fe}$, 98.0\% $\mathrm{Hg}, 98.3 \% \mathrm{La}, 90.1 \% \mathrm{Ni}, 99.5 \% \mathrm{~Pb}, 99.8 \% \mathrm{Sn}$ and $99.99 \% \mathrm{~V}$. In case of $\mathrm{Cd}, \mathrm{Cu}, \mathrm{Fe}, \mathrm{Hg}, \mathrm{Pb}, \mathrm{Sn}$ and $\mathrm{V}$, the high yield may be due to the high adsorption of metal hydroxides on the system used (Table 3). This is also in agreement with the charge densities of metal ions. Thus these elements can be separated quantitatively according to a single-stage batch procedure. ${ }^{19}$

\section{Effects of mass of cellulose and concentration of zinc on the coprecipitation and time of stirring}

The effects of changes of both the mass of cellulose and the zinc reagent concentration on the coprecipitation of the trace amounts of heavy metals were studied. The recoveries of the metals at $\mathrm{pH}=9$ were examined by changing cellulose mass and the concentration of zinc independently. The effects of changes of cellulose mass and of concentration of zinc on recovery of the metals are shown in Figs. 2 and 3. It is quite clear that cellulose plays an important role in the coprecipitation proccess, because it facilitates and accelerates the process of filtration and acts as a good carrier for the coprecipitation of both zinc hydroxide and heavy metal ions. Small quantities of cellulose were enough to give maximum recoveries for $\mathrm{Cr}, \mathrm{La}, \mathrm{Ni}$ and $\mathrm{V}$, which were not affected by higher quantities of cellulose. $\mathrm{Cu}, \mathrm{Fe}$, $\mathrm{Hg}, \mathrm{Pb}$ and Sn were slightly affected by the increase of cellulose mass and can generally exceed $95 \%$ coprecipitated with $0.1 \mathrm{~g}$ of cellulose. Cadmium has maximum recovery when the zinc reagent is used alone in the coprecipitation process. The efficiency of the coprecipitation process of heavy metal ions $-\mathrm{Zn}(\mathrm{OH})_{2}$ precipitate on cellulose, depends upon the positive nuclear charge of such ions and increases with increasing the latter. Since $\mathrm{Cd}^{2+}, \mathrm{Hg}^{2+}, \mathrm{Sn}^{2+}$ and $\mathrm{Fe}^{3+}$ ions have completely filled or half-filled $\mathrm{n}$-1d sub-shells, these lead to the shielding of the nuclear charges of such ions and to decreasing the adsorption phenomena on cellulose and consequently to lowering their recovery percentage. The coprecipitation of $\mathrm{Cu}, \mathrm{Cd}, \mathrm{Ni}, \mathrm{Hg}$ and $\mathrm{Sn}$ deteriorated rapidly when the concentration of zinc was greater than $100 \mathrm{mg}$ per $50 \mathrm{~cm}^{3}$ solution of the heavy metals. The recoveries of $\mathrm{La}$ and $\mathrm{V}$, on the other hand, were independent of the zinc concentration, when the concentration of the latter was greater than $50 \mathrm{mg}$. The effect of time of stirring on the recovery at constant mass of cellulose $(0.1 \mathrm{~g})$ and constant zinc concentration $(50 \mathrm{mg})$ was studied in the range of $10-120 \mathrm{~min}$ (Fig. 4). Most metals were recovered 

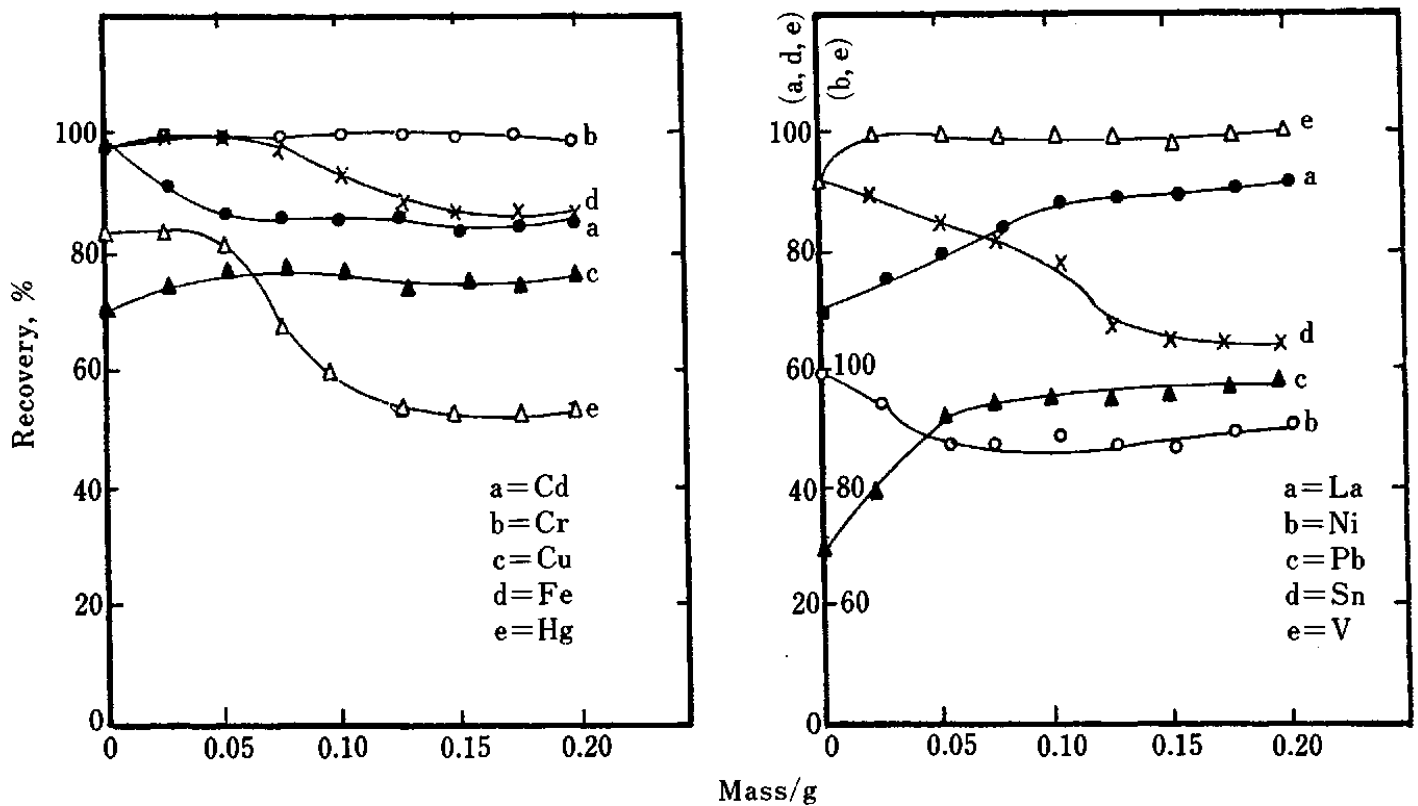

Fig. 2 Effect of changes of mass of cellulose on the coprecipitation of heavy metal at $\mathrm{pH}=9$ and $50 \mathrm{mg}$ of $\mathrm{Zn}^{2+}$.
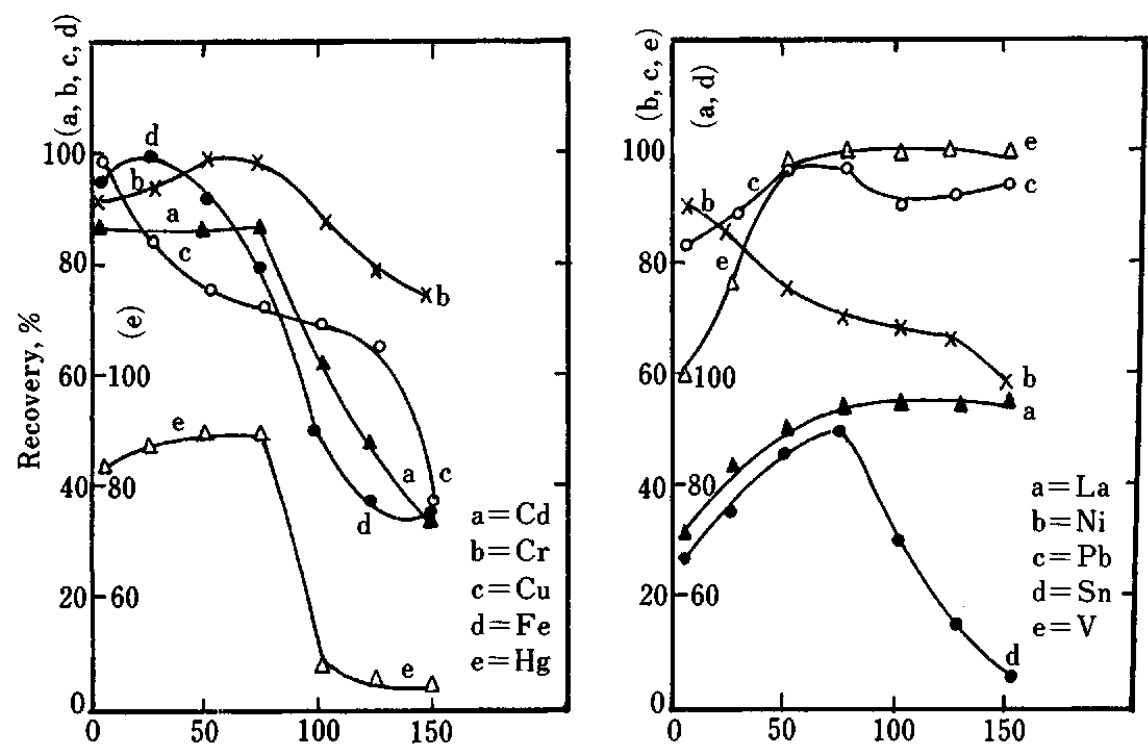

$\mathrm{mg} / \mathrm{Zn}$

Fig. 3 Effect of change of concentration of zinc on the coprecipitation method at $\mathrm{pH}=9$, stirring time $=20 \mathrm{~min}$ (mass of cellulose $0.1 \mathrm{~g}$ ).

after stirring times of $20 \mathrm{~min} ; \mathrm{Cd}, \mathrm{Cr}$ and $\mathrm{Ni}$ were recovered after $10 \mathrm{~min}$ only.

\section{Analytical applications}

Analytical separation procedures for trace elements can be strongly interfered with matrix constituents e.g. alkali and alkaline earth elements. For this reason, the reliability of the tested preconcentration method is examined in the presence of the possible matrix elements. The recoveries of the heavy metals on cellulose-zinc hydroxide in the presence of $\mathrm{Li}^{+}, \mathrm{K}^{+}, \mathrm{Cs}^{+}, \mathrm{Mg}^{2+}, \mathrm{Ca}^{2+}$, $\mathrm{Ba}^{2+}, \mathrm{Sr}^{2+}$ and $\mathrm{Be}^{2+}\left(10\right.$ or $\left.100 \mathrm{mg} \mathrm{dm}^{-3}\right)$ were studied. The results indicate that the matrix ions have little effect on the recovery percentage of the metals studied. However, the $\mathrm{Mg}^{2+}$ ion $\left(3.0 \mathrm{~g} \mathrm{dm}^{-3}\right)$ has a great effect on the recovery percentage $(2-12 \%)$. The effect of $\mathrm{Ca}^{2+}$ in sea level $\left(1.0 \mathrm{~g} \mathrm{dm}^{-3}\right)$ concentration has slight interference. The analytical results of seawater collected at coastal area (Dubai, UAE) at Gulf and Lake in Dubai (waste water) are shown in Table 4. On the other hand, the 


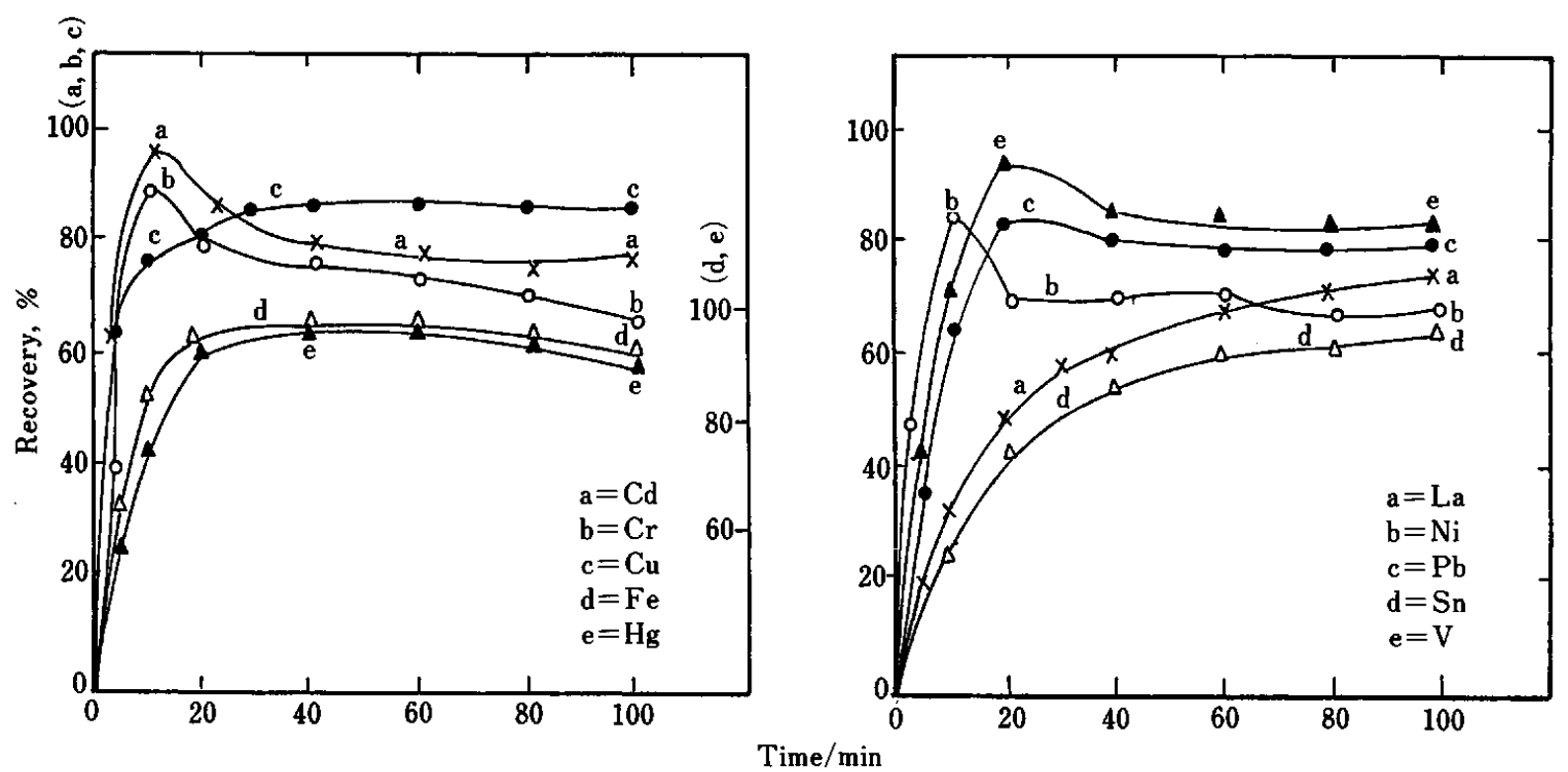

Fig. 4 Effect of stirring time on the coprecipitation of the ten heavy metals $(\mathrm{pH}=9$, mass of cellulose $=0.1 \mathrm{~g}$ and amount of zinc in solution $=50 \mathrm{mg}$ ).

Table 4 Multi-elements analysis of seawater in the Gulf (Dubai Coast, UAE), concentration, $\mu \mathrm{g} \mathrm{dm}^{-3}$, mean values $\pm \mathrm{SD}$ and relative standard deviation $(\%)$

\begin{tabular}{ccccc}
\hline \multicolumn{2}{c}{ Open Gulf } & \multicolumn{2}{c}{ Lake Dubai (waste water) } \\
\hline $\mathrm{Cd}$ & $0.09 \pm 0.01$ & $0.11 \%$ & $0.15 \pm 0.02$ & $0.13 \%$ \\
& $(0.05-4.3)$ & & & \\
$\mathrm{Cr}$ & $0.17 \pm 0.02$ & 0.12 & $0.38 \pm 0.05$ & 0.13 \\
& $(0.15-9.0)$ & & & \\
$\mathrm{Cu}$ & $0.90 \pm 0.04$ & 0.04 & $1.29 \pm 0.05$ & 0.04 \\
& $(0.01-5.3)$ & & & \\
$\mathrm{Fe}$ & $1.01 \pm 0.03$ & 0.03 & $1.26 \pm 0.02$ & 0.02 \\
& $(0.80-70.0)$ & & & \\
$\mathrm{Hg}$ & $0.05 \pm 0.005$ & 0.10 & $0.10 \pm 0.01$ & 0.10 \\
& $(0.04-0.05)$ & & & \\
$\mathrm{La}$ & $0.29 \pm 0.03$ & 0.10 & $0.35 \pm 0.04$ & 0.11 \\
& $(0.3)$ & & & \\
$\mathrm{Ni}$ & $0.28 \pm 0.04$ & 0.14 & $0.61 \pm 0.05$ & 0.08 \\
& $(0.73-8.2)$ & & & \\
$\mathrm{Pb}$ & $1.00 \pm 0.05$ & 0.05 & $1.21 \pm 0.03$ & 0.02 \\
& $(0.64-16.8)$ & & & \\
$\mathrm{Sn}$ & $0.72 \pm 0.02$ & 0.03 & $0.95 \pm 0.04$ & 0.04 \\
& $(3.0)$ & & & \\
$\mathrm{V}$ & $1.35 \pm 0.04$ & 0.03 & $1.78 \pm 0.03$ & 0.02 \\
& $(0.05-9.11)$ & & & \\
\hline
\end{tabular}

Figures in parentheses indicate the reference levels.

metal contents for $\mathrm{Cd}, \mathrm{Cr}, \mathrm{Cu}, \mathrm{Fe}, \mathrm{Hg}, \mathrm{Ni}, \mathrm{Pb}$ and $\mathrm{V}$ in seawater are in good accordance ${ }^{20-26}$ with those found elsewhere, as shown in Table 4. The standard deviation (SD) and relative standard deviation $\left(S_{\mathrm{r}}\right)$ were found to be $0.01-0.05 \mu \mathrm{g} \mathrm{dm}^{-3}$ and $2.8-13 \%$ respectively (Table 4).
The author would like to express his sincere gratitude to Dr. Gaber El-Faioumy, Creminal Research Center, Dubai, UAE, for carrying out ICP-OES measurements.

\section{References}

1. S. Greenfield, I. L. Jones and C. T. Berry, Analyst [London], 89, 713 (1964).

2. R. Wendt and V. A. Fassel, Anal. Chem., 37, 920 (1965).

3. R. N. Merryfield and R. C. Loyd, Anal. Chem., 51, 1965 (1979).

4. C. W. McLeod, A. Otsuki and K. Okamoto, Analyst [London], 106, 419 (1981).

5. A. Sugimae, Anal. Chim. Acta, 121, 331 (1980).

6. O. F. Kamson and A. Townshend, Anal. Chim. Acta, 155, 253 (1983).

7. S. Olsen, L. C. R. Pessenda, J. Ružička and E. H. Hansen, Analyst [London], 108, 905 (1983).

8. S. Hirata, Y. Umezaki and M. Ikeda, Anal. Chem., 58, 2602 (1986).

9. Y. S. Kim and H. Zeitlin, Anal. Chim. Acta, 46, 1 (1969).

10. V. Hudnik, S. Gomiscek and B. Gorene, Anal. Chim. Acta, 98, 39 (1978).

11. M. Hiraide, Y. Yoshida and A. Mizuike, Anal. Chim. Acta, 81, 185 (1976).

12. M. Hiraide, T. Ito, M. Baba, H. Kawaguchi and A. Mizuike, Anal. Chem., 52, 804 (1980).

13. P. Burba and P. G. Wilimer, Fresenius' Z. Anal Chem., 321, 109 (1985).

14. I. M. Kenawy and M. A. H. Hafez, Anal. Sci., 5, 55 (1989).

15. I. M. Kenawy, M. E. Khalifa and M. M. El-Defrawy, Analusis, 15, 314 (1987).

16. H. Kaiser, Spectrochim. Acta, 2, 1 (1981).

17. I. M. M. Kenawy, Ph. D. Thesis, Bochum University, Germany (1980).

18. P. W. J. M. Boumans and J. J. A. M. Vrakking, 
Spectrochim. Acta, 39B, 1261 (1984).

19. P. Burba, P. G. Willmer and A. Von Bohlen, Fresenius' Z. Anal. Chem. (Chrom 44), 334, 686 (1989).

20. P. Burba and K. H. Lieser, Fresenius' Z. Anal. Chem., 279, 374 (1979).

21. P. Burba and P. G. Willmer, Vom Wasser, 58, 43 (1982).

22. C. Samara and Th. A. Koumtzts, Anal. Chim. Acta, 174, 305 (1985).

23. P. Burba and W. Schäfer, Erzmetall, 34, 582 (1981).
24. J. C. Chu, T. Akagi and H. Haraguchi, Bull. Chem. Soc. Jpn., 58, 3229 (1985).

25. J. Emsley, "The Elements", Clarendon Press, Oxford and New York, 1989.

26. H. Z. Wrembel, Talanta, 30, 480 (1983).

(Received July 10, 1991) (Accepted October 21, 1991) 